\title{
Acompañando al Misterio. Elementos para la realización de la catequesis mistagógica
}

Joao Dos Santos Barbosa Neto1

\section{Resumen}

Este artículo propone presentar los elementos para la realización de la catequesis mistogógica teniendo en cuenta la Sagrada Escritura que proporciona el encuentro personal y profundo de la persona con Jesucristo, y la acción litúrgica que, con sus ritos, favorece la inmersión de la persona en lo trascendente. Una auténtica vida de fe debe tener en cuenta la experiencia de manera integral de todo el proceso catequético que conduce a vivir la instrucción recibida en los misterios celebrados, captando y asumiendo en la propia vida los signos del Eterno.

\section{Palabras clave}

Mistagogía, liturgia, Sagrada Escritura, discípulo-misionero.

La mistagogía es considerada todavía por muchos como un tiempo exclusivo del recorrido de la iniciación cristiana, aunque forma parte de una práctica más amplia de la acción pastoral de la Iglesia que implica a toda la comunidad. Se basa en la meditación del Evangelio, la participación en la Eucaristía y el ejercicio de la caridad para progresar en la vivencia y en el conocimiento más profundo del misterio pascual².

1 Salesiano. Forma parte del Equipo de Formadores del Estudiantado Internacional Salesiano de Teología, Roma, Italia y es profesor en la Universidad Pontificia Salesiana de Roma, Italia.

2 Cf. Sagrada Congregación para los sacramentos y el culto divino, Ritual de la iniciación cristiana de adultos (18-04-1976). RICA 37. 
El magisterio maduró lenta e progresivamente la idea de una catequesis destinada a todos los fieles que fuera capaz de "dar sentido a los sacramentos", para que los conduzcan "a escrutar ese Misterio en todas su dimensión... se trata de procurar comprender el significado de los gestos y de las palabras de Cristo, los signos realizados por Él mismo" (CT 5). El carácter mistagógico de la catequesis se estimula mediante un itinerario que lleva a los fieles a penetrar cada vez más en los misterios que se celebran, de modo que puedan tomar mayor conciencia de la liturgia como auténtico encuentro de amor con $\operatorname{Dios}^{4}$, y entusiasmando el desarrollo de una iniciación mistagógica que pueda progresar a lo largo de la vida 5 .

La acción de la catequesis mistagógica tiene por objeto ayudar a "las personas a insertarse progresivamente en la vida de la Iglesia y en la vida cristiana cotidiana"6. Está ligada a la acción litúrgica y trata de promover el ingreso gradual del fiel al misterio Pascual y en la vida cristiana articulando la vivencia litúrgica a los diversos elementos de la vida cristiana7. Esa trata de llevar a los fieles al encuentro del misterio de Dios, a la luz de la Palabra, de la experiencia de los sacramentos y de la comunidad, que dan un auténtico sentido a la vida cristiana. Valorando la puesta en común de experiencias, esa interpreta los ritos de los sacramentos de la iniciación cristiana, a la luz de la historia de la salvación, haciendo emerger su significado en el hoy de la vida cristiana de los bautizados ${ }^{8}$.

\section{La Sagrada Escritura}

La fe que nace de esta escucha profunda y meditada de la Palabra pone a la persona en relación de comunión con Dios y hace de este

3 Juan Pablo II, Exhortación Apostólica Catechesi Tradendae (16-10-1979). CT 37.

4 Benedicto XVI, Exhortación Apostólica postsinodal Sacramentum Caritatis (22-022007). SC 64.

5 Francisco, Exhortación Apostólica Evangelii Gaudium (24-11-2013). EG 166.

6 A. M. Aitken, "Des nouvelles pratiques mystagogiques". Ecclésia 12 (2011) 22-25, 22.

7 Cf. R. Lacroix, "Conversione, catecumenato e dinamica mistagogica", Rivista di Pastorale Liturgica 330:5 (2018) 36-39, 38.

8 Cf. M. P. Ritzenthaler, “Temps de mystagogie à vivre avec les néophytes”, Célébrer 396 (2013) 15-17, 16. 
vínculo una clave de lectura e interpretación de la propia realidad`. La Palabra proporciona un encuentro tan profundo y personal con el Verbo de Dios, Jesucristo, que es capaz de renovar y reorientar la conciencia y el corazón de las personas ${ }^{10}$.

Entrar en el misterio por medio de la Palabra, significa hacerla resonar en el ser y en la vida cotidiana, inaugurando un fecundo diálogo que permita a Dios hablar directamente con la persona en el momento histórico en el que ella lee el texto bíblico. Paso a paso, esta Palabra va plasmando su ser y moldeando su vida, como una respuesta al don de amor proveniente de este encuentro íntimo y significativo "con una Persona, que da un nuevo horizonte a la vida y, con ello, una orientación decisiva”"

Es fundamental que en este itinerario el fiel progrese en la meditación del Evangelio, lo saboree más profundamente y profundice la comprensión de las Sagradas Escrituras ${ }^{12}$. Así, el texto bíblico podrá convertirse en Palabra en la vida de la persona, resonando en su cotidianidad la presencia amorosa de Dios que ilumina los acontecimientos cada vez que se lee, se escucha y se medita su Palabra.

\subsection{La homilía mistagógica}

La acción del Espíritu Santo mediante la Palabra de Dios proclamada genera la purificación del corazón de los fieles que la escuchan atentamente, guiándolos a la realidad divina que los envuelve ${ }^{13}$. En la homilía, el predicador, dejándose guiar por el Espíritu Santo, se convierte en instrumento de diálogo que hace resonar en el corazón del pueblo la Palabra del Señor, como "fuente constante de renovación y de crecimiento" (EG 135) capaz de transmitir "ánimo, aliento, fuerza, impulso" (EG 139).

9 Cf. J. S. Barbosa Neto, "Dalla fede alla virtù: un cammino catechetico mistagogico di discernimento", en M. T Spiga (ed.), Congresso Internazionale Giovani e scelte di vita. Prospettive educative. Vol. 2: Comunicazioni e Buone Pratiche, Roma 2019, 220-228, 225.

10 Cf. Benedicto XVI, Exhortación apostólica postsinodal Verbum Domini (30-092010). VD 11.

11 Benedicto XVI, Carta Encíclica Deus Caritas Est (25-12-2005). DCE 1.

12 Cf. RICA 37-39.

13 Cf. A. Romano, L'Omelia come rito comunicazionale, Roma 2015, 33. 
Esa constituye el "símbolo dinámico del encuentro de la Palabra de Dios con la palabra humana que se hace eco de una palabra pronunciada por el Padre"14. Corresponde entonces al predicador actuar en el proceso de este diálogo, donde velando por la integridad de la Revelación y evidenciando la unidad de la Sagrada Escritura, hace síntesis del mensaje evangélico ${ }^{15}$.

El predicador debe tratar de actualizar la Palabra para que ilumine, dé nuevo significado a las situaciones de la vida, responda a las inquietudes, conforte los corazones y oriente nuevos caminos transformando la vida del pueblo ${ }^{16}$. Él no debería instrumentalizar el texto bíblico concentrándose en moralismos, sino meditarlo profundamente. Para eso es necesario dedicar tiempo suficiente al "estudio, oración, reflexión y creatividad pastoral" (EG 145), de modo que la Palabra lo interpele, lo exhorte, lo mueva. En fin, que la Palabra renueve todas las dimensiones de su vida ${ }^{17}$.

A partir de su propia experiencia vivida con la Palabra y bajo la guía creativa del Espíritu Santo, el predicador realizará en la homilía la importante tarea de actualización "hic et nunc" de la salvación, orientando los estilos de vida cotidiana como la levadura de santificación de la cultura y de las sociedades"18. Se sugiere que él destaque el mensaje central del texto y utilizando un lenguaje positivo ${ }^{19}$, pueda vincular el mensaje del texto bíblico con la situación que vive el pueblo ${ }^{20}$, o a partir de cualquier hecho que la Palabra pueda catalogar fuertemente ${ }^{21} \mathrm{O}$ incluso utilizar imágenes y ejemplos que cooperen en la comprensión de la gente 22 .

14 Romano, L'Omelia come rito comunicazionale, 40.

15 Cf. EG 143-144.

16 Cf. J. S. Barbosa Neto, "Princípios para ações da pastoral e animação bíblica", Revista de Catequese 147 (2016) 42-55, 48.

17 Cf. EG 151.

18 Romano. L'Omelia come rito comunicazionale, 42.

19 Cf. EG 159.

20 Cf. EG 154.

21 Cf. EG 155.

22 Cf. EG 157. 
La homilía hace que el encuentro con la Palabra sea cada vez más comprensible, profundo y fascinante, tocando lo que viven las personas y animándolas a percibir en ello la presencia de $\operatorname{Dios}^{23}$. Así, además de expresar el fervor y la intensidad del amor del predicador a la Palabra, hará arder el corazón de las personas despertando el deseo de progresar en el camino del Evangelio.

\subsection{Formación/preparación de la liturgia dominical de los líderes pastorales}

Es muy importante que la liturgia dominical se prepare con tiempo y en presencia de los miembros de las pastorales implicadas. Este encuentro tiene como objetivo la unidad y la convergencia de la celebración en torno al mensaje central de la liturgia.

Para este momento de formación y de preparación, se recomienda la práctica de la Lectio Divina como el método de orar la Palabra para la profundización de las lecturas del domingo. La buena ejecución de la Lectio Divina favorece la apertura del corazón a Dios, estableciendo un encuentro íntimo entre el fiel y su Señor, de modo que él participe de su misterio.

Este método se compone de cuatro pasos, siendo el primero dedicado a la lectura para tener un primer contacto con el texto, buscando responder a la siguiente pregunta: ¿qué dice el texto? Una persona es invitada a hacer la lectura en alta voz, entonces todos pueden repasar la lectura imaginando la escena descrita, el lenguaje y el contexto.

El segundo paso es la meditación, donde las personas son invitadas a responder individualmente: ¿qué me dice el texto? ¿Qué valores están presentes en este texto? La atención se vuelve a las particularidades del texto, las acciones y las conversaciones del Señor, las actitudes de los personajes, a las notas a pie de página de la Biblia... se busca repasar mentalmente el texto, colocarse dentro del pasaje y escuchar al Señor que habla directamente a la persona.

23 Cf. Barbosa Neto, Princípios para ações da pastoral e animação bíblica, 50. 
El tercer paso es la oración, es la respuesta del fiel a la Palabra, la apertura de su corazón que está dispuesto a iniciar el diálogo y acoger las inspiraciones espirituales de Dios. Se sugiere motivar a los participantes a escribir la oración en un cuaderno individual.

El cuarto paso es la contemplación, donde las personas están llamadas a tomar decisiones, guiadas por la pregunta: ¿qué hace la $\mathrm{Pa}-$ labra en mí? Este último paso busca asumir una nueva actitud, postura o mentalidad a la luz de la experiencia de Dios vivida en la Sagrada Escritura.

Después de la contemplación, el grupo está llamado a compartir las experiencias de la Lectio Divina, buscando relacionarlas con la vida, los eventos y celebraciones de la comunidad. Así, inmersos en la Palabra, pueden comenzar a pensar en la totalidad de la celebración y a colaborar más profundamente.

\subsection{Catequesis / Catequista}

La catequesis "es un anuncio de la Palabra y está centrado en ella" (EG 166), por eso el catequista debe iniciar a los catequizandos en la escucha y la lectura de la Biblia, en particular del Evangelio dominical. La fuerza de su acción deberá concentrarse en presentar a una persona, Jesucristo, promoviendo así un encuentro personal a través de la Palabra, de modo que emerja una relación profunda y se establezca un diálogo de comunión, donde no se hable de Dios sino a Dios ${ }^{24}$.

Este camino es una invitación "a crecer en la fidelidad al estilo de vida del Evangelio" (EG 168), por eso se debe motivar la adquisición de una mayor familiaridad con la Sagrada Escritura y una progresiva profundización de los textos. Existen diversos métodos e itinerarios, por lo que corresponderá a la comunidad aplicar aquel que le sea más familiar.

24 Cf. Barbosa Neto, Dalla fede alla virtù, 223. 


\subsubsection{Método catequístico y popular de la lectura de la Palabra}

Aquí presentamos el modelo en el que el catequista desarrolla el anuncio de la Palabra. En este método, el catequista reunido con los catequizandos abre la Biblia (cada uno con su Biblia) en el pasaje correspondiente al Evangelio (o una de las lecturas) del domingo anterior. Se inicia el momento con la invocación del Espíritu Santo, y luego el catequista (o alguien previamente indicado) hace la lectura del texto en alta voz. Terminada la lectura, se invita al silencio, donde cada uno se esfuerza por recordar el texto repasándolo mentalmente.

Pasados unos minutos, se invita al grupo a releer el texto de modo individual y en voz baja, subrayando los verbos para así identificar las acciones, órdenes y principios de Dios para nosotros. Es importante hacerles notar las indicaciones de las notas a pie de página de las Biblias que sirven como puntos explicativos.

Después de estos pasos, están llamados a elegir uno o dos versículos de la lectura, y a transcribirlos en un cuaderno. En este cuaderno, además de los versículos elegidos ellos deberán responder a dos preguntas: ¿Qué me dice Dios a través de estos versículos? ¿Por qué me sentí tocado por ellos? ¿Qué debo hacer para asumir en mi vida el mensaje de este texto?

Por último, se abre un buen espacio para compartir, motivándolos para que el momento sea de espontaneidad y familiaridad, no es un lugar para moralismos, juicios y pequeñas homilías, sino de compartir la experiencia espiritual del texto.

\section{La acción litúrgica y sus ritos}

La acción litúrgica por medio de sus símbolos y de sus ritos, promueve la apertura del ser humano a lo trascendente y por ser Epifanía del misterio, se convierte en el espacio favorable para que se revele en la celebración ${ }^{25}$. Inmersa en esta acción celebrativa, pedagógicamente la persona es insertada en una nueva realidad de vida

25 Cf. G. Boselli, O sentido espiritual da liturgia, Brasília 2014, 18. 
comunitaria y es educada al encuentro y la comunión con otras personas y con Dios ${ }^{26}$.

Desgraciadamente, por diversas razones, existen al menos dos actitudes que derrotan todo el proceso pedagógico de la liturgia: el automatismo en la repetición de los gestos y tomar por seguro que todos en la asamblea comprenden el significado de cada acción realizada en la celebración. Esta situación vacía la comprensión espiritual del acto litúrgico, bloquea la transmisión de su sentido auténtico que da la posibilidad de conocer a Jesucristo y, en consecuencia, se vuelve irrelevante en la vida espiritual de la persona ${ }^{27}$. Se hace urgente, a través de la acción mistagógica, activar medios que eduquen a las personas a reconsiderar el ritual en la celebración litúrgica de modo que puedan abrirse al misterio, a las dimensiones del Otro ${ }^{28}$. En un movimiento recíproco, sólo será posible redescubrir el sentido de lo que se celebra, cuando él mismo sea capaz de dar sentido a la existencia de la persona que lo celebra ${ }^{29}$.

Según el papa Benedicto XVI, la catequesis mistagógica debe ayudar a la persona a vivir la realidad celebrada, por eso ella "ha de preocuparse por introducir en el sentido de los signos que están contenidos en los ritos, (mostrando así) el significado de los ritos para la vida cristiana" (SC 64). En esta línea, Papa Francisco estimula que esta catequesis esté abierta a todos los fieles, durante todo el año litúrgico e identifica dos importantes características: "la necesaria progresividad de la experiencia formativa donde interviene toda la comunidad y una renovada valoración de los signos litúrgicos de la iniciación cristiana" (EG 166).

Es necesario desarrollar una reflexión sobre la dinámica ritual, para hacer comprender que el rito es la apertura a Alguien, que a cada celebración se renueva, que a través de él la fe se desarrolla y madura,

26 Cf. G. Bonaccorso, Il Rito e l'Altro, Città del Vaticano 2012, 2 ed., 359.

27 Cf. Boselli, O sentido espiritual da liturgia, 30.

28 Cf. F.Poulet, "Apprendre à célébrer: éduquer et inicier au mystère", en: I. Morel - J. Molinario - H. Derroitte (eds.), Les catéchètes dans la mission de l'Église, Paris 2016, 181-193, 190.

29 Cf. Bonaccoso, Il Rito e l'Altro, 360. 
pues revela el acontecimiento de salvación y conduce al conocimiento de Cristo ${ }^{30}$. Ahora bien, toda acción litúrgica es acción de Cristo, por lo tanto la comprensión de la ritualidad, de los gestos y de los símbolos, es vía necesaria para entrar en relación con el misterio, y así a través de la liturgia llegar al conocimiento de Cristo, que es el principio de conocimiento e interpretación de la liturgia misma ${ }^{31}$.

La concordancia de las disposiciones interiores en el acto litúrgico (donde en el lenguaje simbólico los gestos se unen a las palabras) es fundamental para evitar el ritualismo y favorecer una buena condición en la que la persona pueda vivir lo que se celebra ${ }^{32}$. Por eso, la mistagogía actúa con la pedagogía inherente de la celebración litúrgica, contribuyendo a la comprensión y al desarrollo del significado de la acción litúrgica, de modo que el fiel pueda celebrar y vivir en profundidad el misterio ${ }^{33}$.

\subsection{Celebración y ritos litúrgicos}

Los ritos de la liturgia son como el lugar donde el cuerpo se une a la palabra y el ser humano se hace presente ante Dios, que a su vez se manifiesta y se comunica con el hombre. En este contexto la acción mistagógica puede favorecer la interiorización de lo que se experimenta en la liturgia, pues la comprensión del sentido espiritual del rito genera un conocimiento integral que envuelve todas las dimensiones del ser humano, renovando y esculpiendo la vida del bautizado a partir de la experiencia realizada.

Es fundamental velar por una ritualidad bien hecha, a través de una adecuada ambientación del espacio celebrativo, previa organización de todos los pasajes del rito con la debida distribución de funciones y ensayos. A esto se suma la pertinente preparación del ministerio de música, la debida elección de los cantos en línea con la liturgia celebrada y la disposición de todo material y objetos necesarios para que la acción litúrgica puedan fluir normalmente.

30 Cf. Lacroix, Conversione, catecumenato e dinamica mistagogica, 38.

31 Cf. Boselli, O sentido espiritual da liturgia, 31.

32 Cf. SC 64.

33 Cf. Aitken, Des nouvelles pratiques mystagogiques, 24-25. 
No se trata de explicar el rito o los símbolos durante la celebración, sino de evidenciar alguna parte o llamar la atención sobre algún detalle particular, motivando así la mayor participación y comprensión de la asamblea en la acción litúrgica. De este modo, se hace posible el proceso de interiorización de lo que se experimenta en el ritual, en el que la persona toma conciencia de que el misterio celebrado se realiza en la existencia concreta, de modo que se registren en la vida del fiel las experiencias probadas en la liturgia.

\subsection{Catequesis / Catequista}

Para la realización de la catequesis mistagógica una buena intuición son las salas mistagógicas, es decir, espacios dedicados a la realización de estos encuentros. Se planifican como un ambiente orante, capaz de despertar el sentido del Sagrado y favorecer la inmersión de la persona en el misterio.

Es importante que la sala este organizada de forma acogedora y armoniosa (centralidad y progresión del mensaje bíblico; sintonía en los colores; atención a la iluminación y la ventilación) y con una disposición adecuada de los muebles (respetando la estructura y los límites de la sala) de modo que pueda contribuir a la profundización ritual celebrativa. Algunos artículos pueden ser considerados indispensables: la Palabra (la Biblia o el Leccionario), la cruz o el Resucitado, artes sacras (pinturas, mosaicos o banners), velas y si es posible el incienso.

Como se trata de compartir, es fundamental que las personas estén en círculo o en medio círculo, dependiendo del lugar pueden incluso estar sentadas alrededor de una mesa debidamente preparada. En todo caso, se debe evitar la disposición que recuerda a una escuela, es decir, las sillas alineadas y volcadas en una misma dirección.

Es fundamental que los participantes en esta catequesis se sientan acogidos desde la llegada, favoreciendo así un ambiente que facilite el intercambio de experiencias. Ellos serán invitados a manifestar su propio parecer (alegría, preocupación, alivio, convicción...), o a evidenciar algún símbolo o recuerdo sensorial (música, 
luz, incienso, vela, agua, cirio pascual...) por el cual se sintieron tocados por Dios.

Como se ve en este ejemplo la catequesis mistagógica busca captar la experiencia de la persona a partir del rito celebrado, a través de los símbolos, gestos, palabras y objetos contenidos en la celebración. No se trata de una lección explicativa, sino de compartir lo que se ha experimentado, lo que han significado los elementos rituales para la persona misma, en la que se ha sentido tocada.

El catequista está llamado a acompañar a las personas en un proceso gradual de meditación y reflexión sobre los símbolos y gestos litúrgicos, haciéndoles superar los primeros significados y adentrarse en el misterio que revela la comunión e intimidad con Jesucristo. Así, el catequista es la guía de una aventura interior, en la que "hace pasar una vida en el misterio y a través del misterio en la propia comunión de Dios" ${ }^{34}$.

\section{La vida de fe (discípulo-misionero)}

La experiencia realizada en la celebración litúrgica lleva al bautizado a abrirse a Dios, lo motiva a traer a su cotidiano la gracia vivida en el rito y lo hace testigo del encuentro con el Resucitado. Así, abandona gradualmente la distracción de la oración, que como consecuencia lo distrae en la vida espiritual, para asumir una posición más convencida y dedicada a partir de la experiencia del amor de Dios en la vida de fe a través de los símbolos y los signos de la ritualidad de la celebración.

La maduración de algunas actitudes y posturas celebrativas, tales como: la sensibilización e interés al símbolo, la atención a las particularidades del rito, y la conciencia de los gestos realizados, favorecen el ingreso del fiel en el misterio. En este itinerario se renueva profundamente la experiencia de la vida de fe que se prolonga orientando las opciones y dando nuevo significado a la vida concreta.

34 F. Debuyst, L'entrée en liturgie: introduction à l'oeuvre liturgique de Romano Guardini, Paris 2008, 80. 
La persona implicada en este proceso se ve fortalecida por la acción del Espíritu Santo a través de la práctica eclesial que recupera la conciencia de ser comprendida de nuevo, haciendo posible el paso del sentimentalismo a la convicción en el seguimiento de Cristo y al compromiso de la vida comunitaria. La vida de fe se convierte entonces en el lugar donde Dios se une al creyente y se revela, proporcionando a él en este encuentro una experiencia de comunión entre la Escritura, la celebración litúrgica y la vida.

Este encuentro genera la motivación profunda de la que emerge el amor que da la convicción de dejar todo y permanecer con Dios, pues al lado de Él todo se hace infinitamente mayor que todo lo que existía antes, la vida cobra un sentido más pleno. El fiel, escuchando la Palabra y meditando el rito, reconoce el misterio de la vida en Dios y asume en su existencia la condición de discípulo misionero, por la que trasmite y testimonia la fe a otras personas.

\section{Conclusión}

El presente artículo parte de tres puntos básicos del camino mistagógico (la Palabra, la Liturgia y la vida del bautizado) presentando una reflexión catequística conjugada de modo pedagógico que desemboca en propuestas realizables. En este itinerario, la catequesis mistagógica se funda en bases que permiten su comprensión como elemento educativo y su acogida como método pedagógico, de modo que se aproveche una verdadera experiencia del misterio celebrado y se favorezca una verdadera vivencia cotidiana de la fe transmitida, enseñada y madurada. 